\title{
Japoto: sitio manteño residencial de la costa central de Manabí
}

Japoto : site residenciel de la culture manteña, côte centrale du Manabí

Japoto: a residential archaeological site of the Manteña culture on the central coast of Manabí

Jean-François Bouchard

\section{(2) OpenEdition}

Journals

\section{Edición electrónica}

URL: http://journals.openedition.org/bifea/1709

DOI: 10.4000/bifea.1709

ISSN: 2076-5827

\section{Editor}

Institut Français d'Études Andines

\section{Edición impresa}

Fecha de publicación: 1 diciembre 2010

Paginación: 479-501

ISSN: 0303-7495

\section{Referencia electrónica}

Jean-François Bouchard, « Japoto: sitio manteño residencial de la costa central de Manabí », Bulletin de l'Institut français d'études andines [En línea], 39 (3) | 2010, Publicado el 01 junio 2011, consultado el 07 diciembre 2020. URL : http://journals.openedition.org/bifea/1709; DOI : https://doi.org/10.4000/ bifea. 1709

\section{(a) $\mathbb{Q} \Theta \Theta$}

Les contenus du Bulletin de l'Institut français d'études andines sont mis à disposition selon les termes de la licence Creative Commons Attribution - Pas d'Utilisation Commerciale - Pas de Modification 4.0 International. 


\title{
Japoto: sitio manteño residencial de la costa central de Manabí
}

\author{
Jean-François Bouchard*
}

\begin{abstract}
Resumen
Este artículo resume los principales resultados de las excavaciones hechas en el sitio manteño de Japoto (Periodo de Integración) y hace hincapié en su importancia, al afianzar la hipótesis sostenida desde los inicios del proyecto. Muchos de los vestigios encontrados evidencian actividades domésticas, mientras otros sugieren que parte de la población residente perteneció a la élite de un cacicazgo (señorío, jefatura), cuya sede fue Japoto.
\end{abstract}

Palabras clave: cacigazgo, manteño, Manabí, tolas, arquitectura, sepulturas

\section{Japoto : site residenciel de la culture manteña, côte centrale du Manabí}

\section{Résumé}

Cet article fait état des principaux résultats des fouilles réalisées à Jopoto, site de la culture manteña (Période d'Intégration), et conforte l'hypothèse initiale du projet. Les fouilles ont révélé de nombreux vestiges domestiques ainsi que divers éléments qui permettent de penser que la population de Japoto appartenait à une élite correspondant au siège d'un pouvoir régional (chefferie).

Mots clés : chefferie, manteño, Manabí, tolas, architecture, sépultures

* UMR 8096, ARCHAM, CNRS. Nanterre-Cedex (París, Francia). E-mail: jean-francois.bouchard@ mae.u-paris10.fr 


\title{
Japoto: a residential archaeological site of the Manteña culture on the central coast of Manabí
}

\begin{abstract}
This paper summarizes the main discoveries at Japoto, an archaeological site belonging to the Manteño culture during the Integration Period. Many of the features documented provide evidence of domestic activities. As we hypothesized at the very beginning of our project, Japoto may have been the redisential site for the elite members of a chiefdom ruling this northern part of the Manteño territory.
\end{abstract}

Key words: chiefdom, Manteño, Manabi, tolas, architecture, tombs

Desde 2002 estamos estudiando un sector de la costa central del Ecuador en la provincia de Manabí (fig. 1). A este estudio se han asociado varias instituciones científicas y académicas que se centran en el sitio arqueológico de Japoto (fig. 2), cerca del balneario de San Jacinto, al lado de la carretera asfaltada que une Puerto Viejo con Bahía de Caráquez. En la literatura científica fue Emilio Estrada el primero en mencionar el sitio arqueológico en su libro Arqueología de Manabí, bajo el nombre de Charapoto (Estrada, 1957). Sin embargo, en esa época, no hubieron estudios ni excavaciones en el terreno.

Otras referencias databan de la Conquista, en el siglo XVI, puesto que la región fue uno de los primeros descubrimientos realizados por las expediciones españolas. Varios cronistas mencionaban un Charapoto que podría ser una alteración de la palabra vernácula Japoto. Pero el sitio se conoció también con el nombre de Amotopse en la época de la Conquista, lo que se pudo inferir de un mapa sobre las primeras expediciones españolas en las costas ecuatorianas (Morales y Eloy, 1962).

Estas expediciones de Pizarro alcanzaron primero la costa del Pacífico en Colombia y luego, en el actual Ecuador, Esmeraldas y Atacames (Tacaméz), Jama y Coaque y finalmente, la costa al sur del río Chone hasta llegar al río Puerto Viejo, un poco más al norte de Manta. Es decir, en el Ecuador las poblaciones indígenas que vivían cerca de la línea equinoccial fueron las primeras en recibir los efectos de la «conquista», y por lo tanto padecieron sus impactos justo antes del descubrimiento del Tahuantinsuyu por Pizarro. En el siglo XVI, Puerto Viejo fue un centro estratégico donde los españoles establecieron una fuerte base para albergar los primeros heridos y enfermos de su tropa sin tener que llevarlos de regreso hasta Panamá. Entonces fue un «puerto de entrada» no solamente para los conquistadores sino también para los microbios y otros virus que traían los españoles. Mucho más que las batallas, la difusión fulminante de las enfermedades importadas contribuyeron a la drástica caída demográfica de esta costa: en pocos decenios desapareció la mayor parte de la población indígena. 


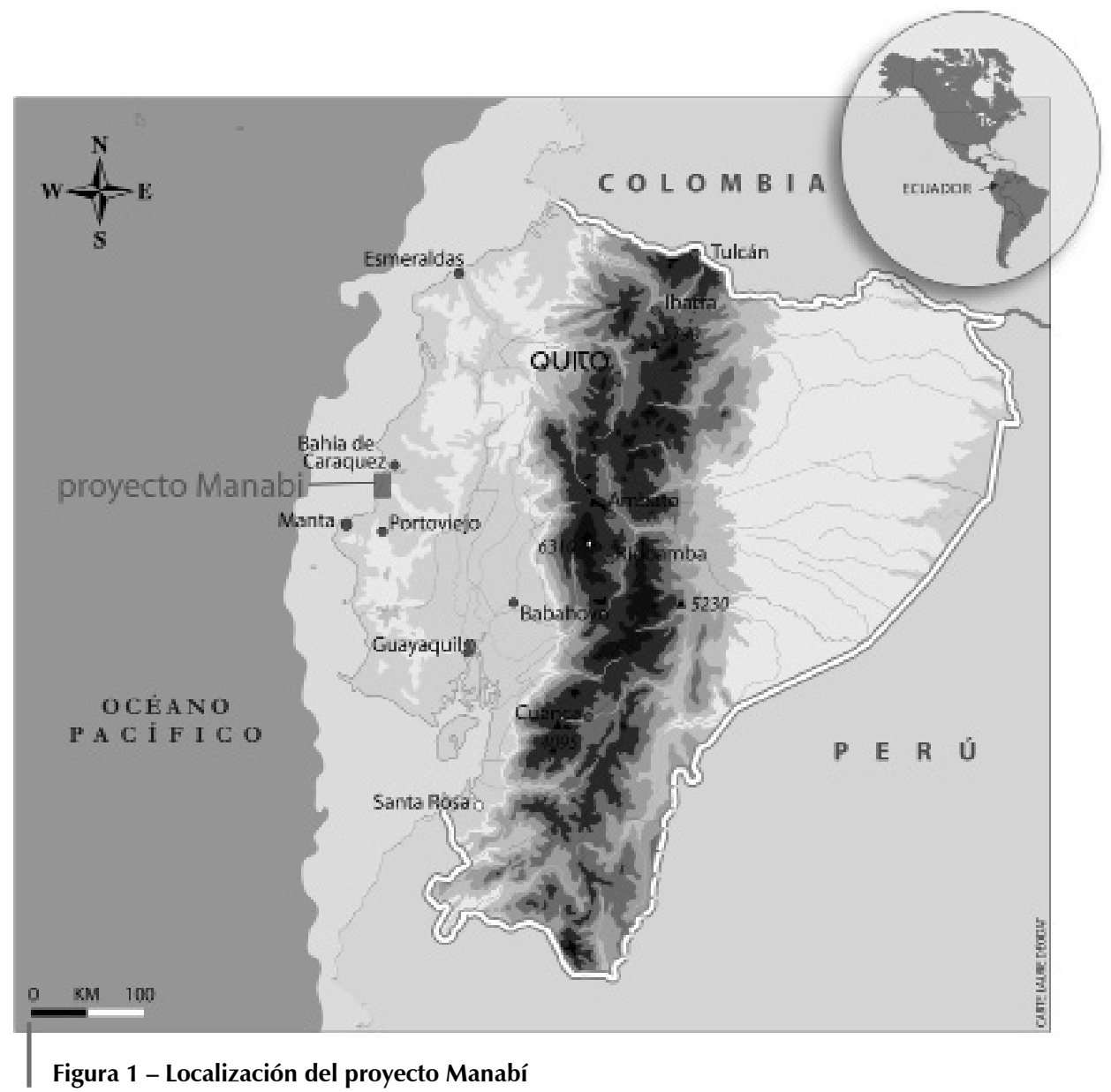

No son numerosos ni detallados los datos históricos fiables que se refieren a este periodo. Entre los que relatan estos datos figuran ilustres y fiables testigos de aquellos tiempos como Benzoni, Cieza de León, Estete, Cabello Balboa, de Jerez, Pizarro y Trujillo. En su mayoría, dedican pocas páginas a la región y a los nativos encontrados. Para la época anterior a la Conquista existe una cierta confusión acerca del dominio de los incas. La conquista de la sierra ecuatoriana es efectiva sin lugar a dudas, pero la conquista de la costa parece mucho más discutible. Aparentemente, los primeros españoles en llegar descubren pueblos nativos costeros que no han perdido el control de sus tierras, aunque también se dice que algunos ya pagan un tributo al Inca.

Algunos relatos (por ejemplo, Cieza de León) cuentan que varios pueblos oponen resistencia y hacen trampas a las tropas del Inca, logrando evitar su victoria definitiva. Aparentemente el límite serrano del imperio Inca pasa más al norte de la línea ecuatorial, mientras que en la costa, la región de Tumbes es el límite 


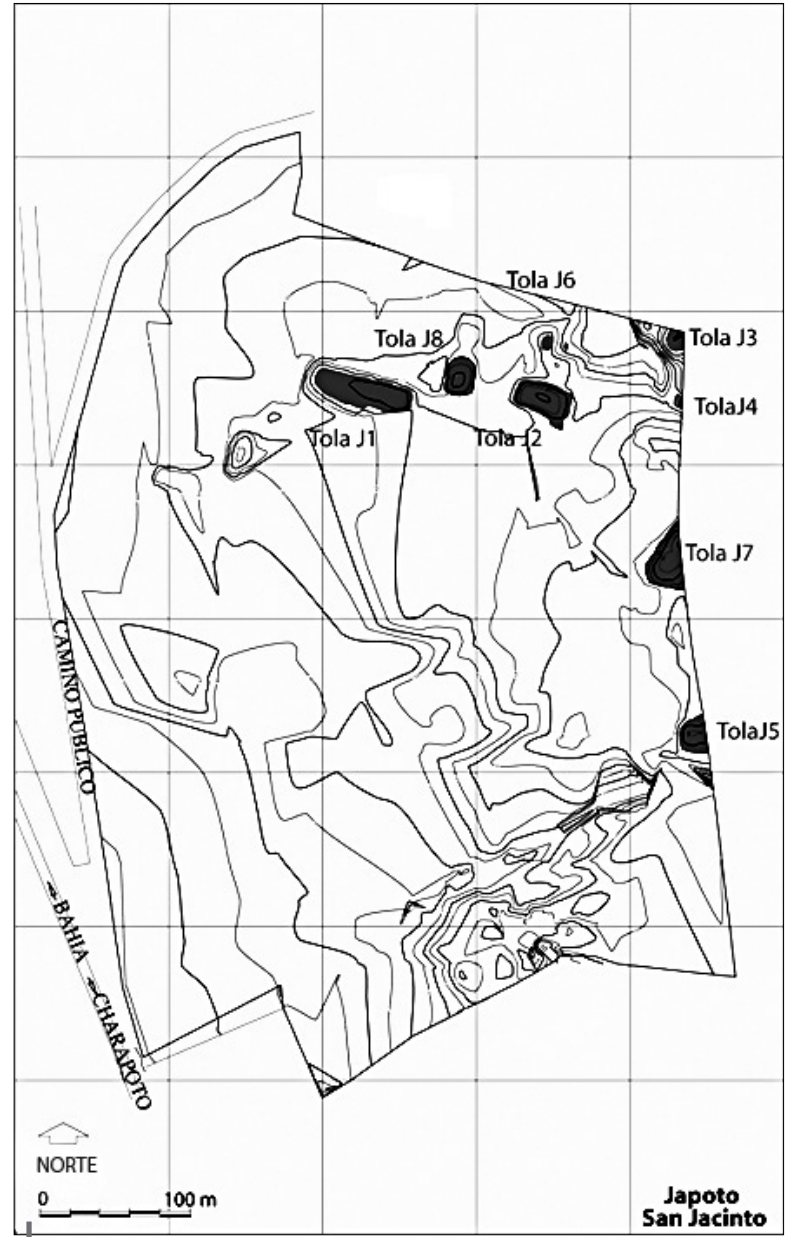

Figura 2 - Plano de la finca y localización de las tolas estudiadas norte. Por lo tanto, las costas entre el río Chone y el Guayas parecen haber sido un territorio todavía libre, así como la isla de la Puna.

Como lo muestra la literatura, los estudios de Arqueología han dejado un poco de lado el territorio de la costa central. Además se sabe que el Periodo Formativo y el de los Desarrollos Regionales de la costa se han estudiado con más atención que el Periodo de Integración que nos interesa ahora. No es el lugar para preguntarse por qué tienen más interés unos periodos que otros, pero debemos admitir que los arqueólogos casi siempre se dedican a tiempos remotos, abandonando los periodos más recientes a los historiadores, aún cuando se trata de épocas o regiones con un mínimo de datos escritos o de archivos de otros tipos.

En resumen, se considera que, durante este Periodo de Integración, se desarrolla en la costa central del Ecuador una tradición cultural que se define usualmente como «cultura manteña-guancavilca» (una de sus apelaciones) 1 .

Aparte de interpretaciones que buscan valorizar los pueblos del último periodo prehispánico, con énfasis sobre la red de comercio marítimo establecida por lo «Fenicios del Ecuador» o la «liga de mercaderes», casi todo lo que se conoce ya pertenece a una época muy remota que ilustran los libros de Saville a principios del siglo XX (Saville, 1907). Por otra parte, no existe para estos pueblos costeros una documentación que permita estudios complejos similares a los de etnohistoriadores como Caillavet, Moreno o Salomón para la sierra. Existe así una doble frustración en cuanto a la época precolombina tardía de la costa ecuatorial.

1 Esta tradición cultural cubre alrededor de 8 siglos. Si miramos otras regiones andinas, podemos decir que, para las épocas tardías, prácticamente es un caso único, puesto que a menudo se suceden de dos a tres (y más) tradiciones en el mismo lapso. 
A juzgar por las informaciones dadas por los cronistas, al llegar a las costas ecuatorianas, los españoles empezaron (o continuaron) sus expediciones de saqueo y encontraron comida abundante y riquezas varias2. Parece que los nativos no se defendieron tanto, a diferencia de los «indios bravos» que poblaban las costas del sur de Colombia. Cieza de León observó que desde Bahía de Caráquez, los nativos tenían otras facciones y características físicas que los de Esmeraldas, Jama y Coaque. Podía ser el indicio de que pertenecían a otro grupo cultural. Sin embargo no hay registro de un nombre específico para este posible nuevo grupo cultural. Es preciso señalar que la Arqueología utiliza términos y apelaciones muy ambiguos para nombrar a los grupos y tradiciones culturales locales. Entonces se habla de una cultura «Bahía de Caráquez» que es obviamente una palabra mixta de cultura colonial, aunque se refiere sobre todo a elementos descubiertos cerca de la ciudad moderna de Manta, como los famosos gigantes de cerámica. Incluso se habla de una cultura «Manta» o manteña, cuando Manta es la nueva palabra que surgió después de la conquista del pueblo indígena Jocay. Ya no se pueden cambiar los usos y costumbres, pero podemos ver cómo el mismo estudio del pasado empieza con el desprecio hacia las culturas nativas que permanen anónimas al ser borradas de la memoria local. De tal modo, poco tiempo después de la conquista española no quedaba nada de ese pasado nativo, mientras que lo que fue un «paraíso de tierras ricas» llegó a ser una tierra pobre y despoblada que no se ha recuperado hasta nuestros días.

Se expondrán algunos resultados del proyecto, obtenidos durante seis temporadas de excavación entre 2003 y 2008 que llevan a una serie de interpretaciones. Muchos temas ya han sido comentados o van a ser detallados por otros colegas en los artículos de este volumen, y es grato darles el crédito de sus hallazgos con la esperanza de que esos vestigios permanezcan como pruebas tangibles del mundo prehispánico de Manabí.

\section{JAPOTO Y LA CRONOLOGÍA}

Hasta la fecha, faltan algunos resultados de las dataciones 14 C y T.L. para el sitio. Sin embargo una primera serie nos indica que existen fechas de cronología 14 C repartidas a lo largo del lapso de tiempo usualmente considerado como el Periodo de Integración (Bouchard et al., 2006). Por otro lado, Karen Stothert, al analizar la cerámica de Japoto, sugiere que se asemeja más bien a ejemplos tempranos de la cerámica manteña conocida en sitios del sur.

Así dice ella en su artículo:

«A primera vista la cerámica de Japoto es más parecida a otros conjuntos fechados a la primera parte de la secuencia elaborada a base de datos

2 Desde las primeras expediciones que salieron de Panamá en busca del Perú (Birú), hay relatos de saqueos y enfrentamientos con los indígenas de la costa del Pacífico (hoy Colombia). Lo que demuestra que dichas expediciones siempre tuvieron como meta principal apoderarse de las riquezas que estaban en manos de los pobladores nativos. 
de la Península de Santa Elena en el sur: es decir, corresponde a la fase Manteña Temprana en la secuencia elaborada por Paulsen (Paulsen, 1970). La cerámica de Japoto es muy similar a la del sitio llamado Los Frailes, paradero ubicado cerca de Machalilla en el sur de Manabí (Mester, 1990). En comparación con Los Frailes, la cerámica de Japoto presenta una amplia variedad de vasijas utilitarias, y una variedad más amplia de formas finas y decoraciones. Algunos rasgos indican que la ocupación de Japoto fue más larga que la de Los Frailes» (Stothert, 2006).

La escasez de materiales tardíos, se debe, según parece, a que los niveles superiores (que corresponden, se supone, a la ocupación tardía) han perdido en gran parte o en su totalidad, los elementos (carbón, cerámica, etc.) presentes muy cerca de la superficie en otros tiempos y que son eliminados por la erosión después del abandono del lugar.

De ser así se propone para Japoto una secuencia tentativa con tres episodios.

- Primera ocupación «antigua» que posiblemente tuvo lugar a principios del Periodo de Integración. Se realizó en un sitio que tenía un aspecto distinto al actual, pues no existían entonces los montículos artificiales (tolas) que dan su aspecto característico al paisaje moderno (figs. 3 y 4 ).
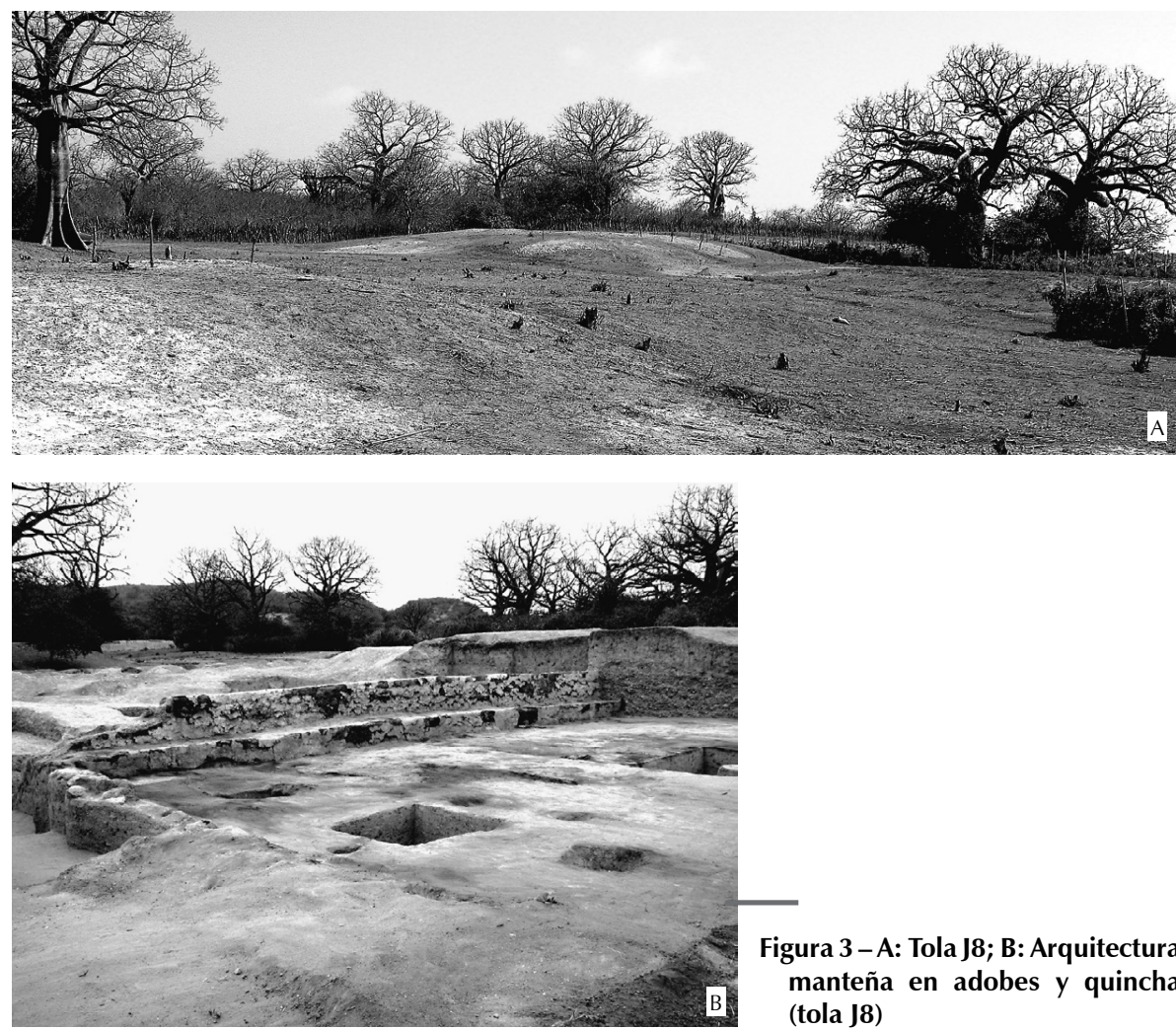

Figura 3-A: Tola J8; B: Arquitectura manteña en adobes y quincha (tola J8) 
Japoto: sitio manteño residencial de la costa central de Manabí
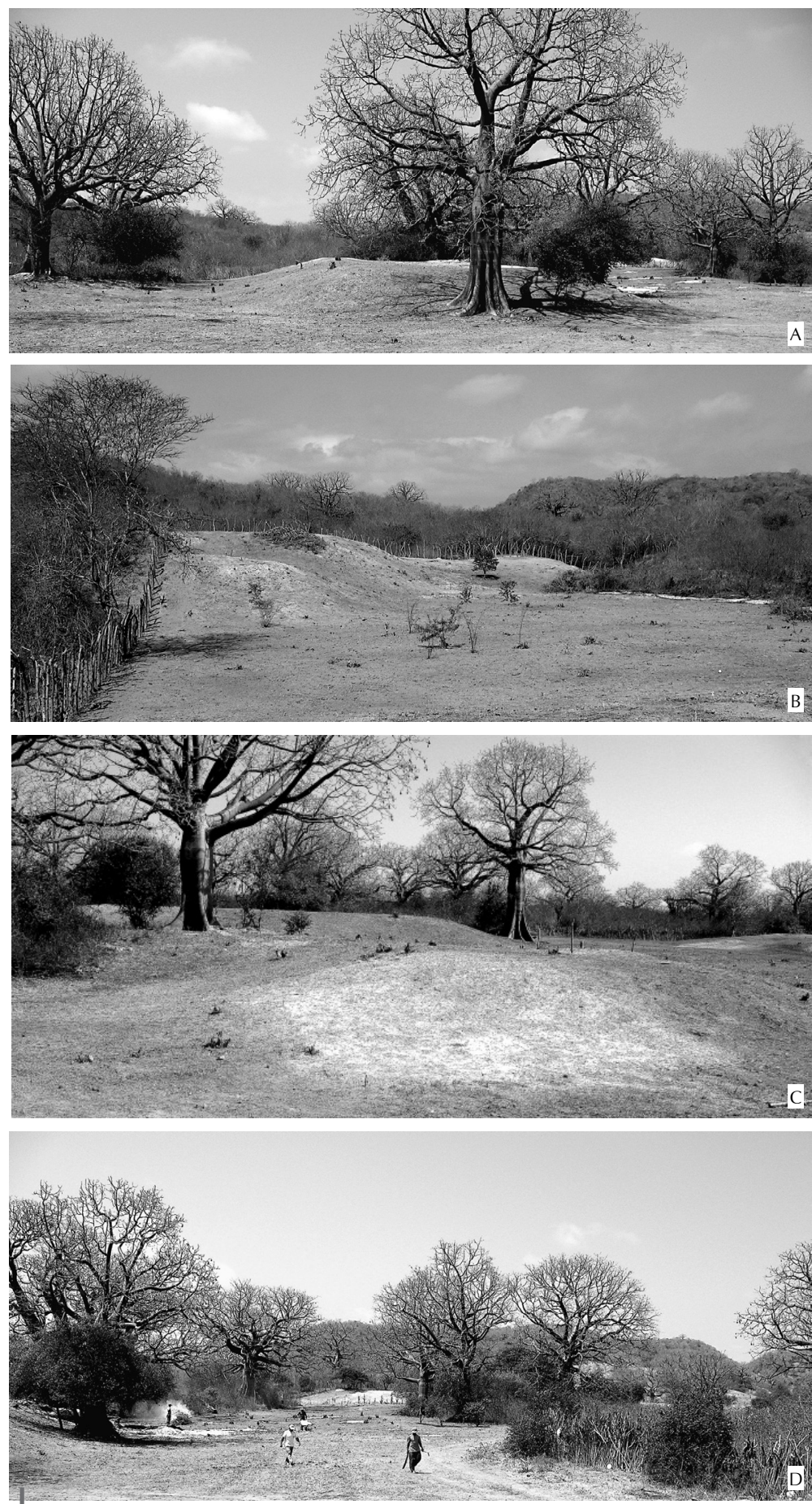

Figura 4 - A: Tola J2; B: Tola J3 y J4; C: Tola J6 y J2; D: Tola J7 
- Serie de ocupaciones más recientes, que adoptan la modalidad de crear plataformas acumulando poco a poco capas de relleno a medida de la necesidad de mantener la plataforma en buen estado. En el relleno, se reconoce cantidad de material cerámico que no se han eliminado de la tierra traída para alzar la tola. En cambio, en los pisos que se han sacado a la luz no quedan prácticamente tiestos esparcidos sino más bien «rasgos» que son indicios de la misma ocupación. En los niveles de relleno también figuran las «intrusiones» como huellas de postes, depresiones cavadas por los habitantes, etc.

- Última ocupación prehispánica: corresponde posiblemente a la época coetánea a la llegada de los primeros conquistadores españoles. Tal como fue mencionado ya, la erosión sobre las tolas durante cuatro siglos hizo que se perdieran en su mayor parte las huellas de ese periodo.

Se puede afirmar que no hubo ningún tipo de asentamiento colonial en Japoto pues no se han encontrado huellas de ocupación. Seguramente los habitantes nativos abandonaron sus viviendas de Japoto. La ausencia de datos precisos condena a un enigma: no se sabe lo que pasó con los habitantes de este pueblo. Tal vez desaparecieron, huyeron y se movieron a aldeas «autorizadas» por los conquistadores.

\section{EVIDENCIAS DOMÉSTICAS Y ARQUITECTURA PÚBLICA}

Uno de los logros del proyecto es haber sacado a la luz vestigios de distintos modelos arquitectónicos. Por otra parte, abundan los elementos que permiten interpretar muchos rasgos de las áreas excavadas en las tolas como evidencias de actividades domésticas. Estos datos conforman evidencias claras de la residencia de gente en el sitio.

Hay numerosos «hornos manabitas», fogones, depósitos de basura y de restos alimenticios con conchas de moluscos, huesos de pescado o de animales terrestres (Guinea 2006; Touchard, 2006). Estos vestigios están presentes en todas las tolas, menos en dos que son casos excepcionales, como se podrá ver más adelante.

Es preciso examinar las modalidades de manejo del fuego y del calor con fines domésticos (figs. 5 y 6). Hay numerosas zonas, horizontales o cóncavas, que se pueden interpretar como la huella limitada de fogones culinarios alimentados por leña. Los más interesantes son los elementos domésticos llamados hornos manabitas. Son depresiones cóncavas de forma globular o hemisférica que tienen paredes endurecidas y rubefactadas por un fuego intenso y largo. Dichos hornos contienen brasas ardientes destinadas a elaborar una comida guisada en ollas en vez de exponer directamente los alimentos al fuego. En toda la provincia de Manabí (y en otras provincias) esta modalidad muy particular de preparar los alimentos sigue en uso y es importante ver que el estudio arqueológico revela el origen nativo de esta práctica.

En la cumbre de la tola J5, se pudo excavar en área un piso totalmente quemado endurecido por el fuego. Este piso parece haber correspondido al suelo interior de una casa hecha de materiales vegetales y perecederos (cañas, madera, hojas 
Japoto: sitio manteño residencial de la costa central de Manabí
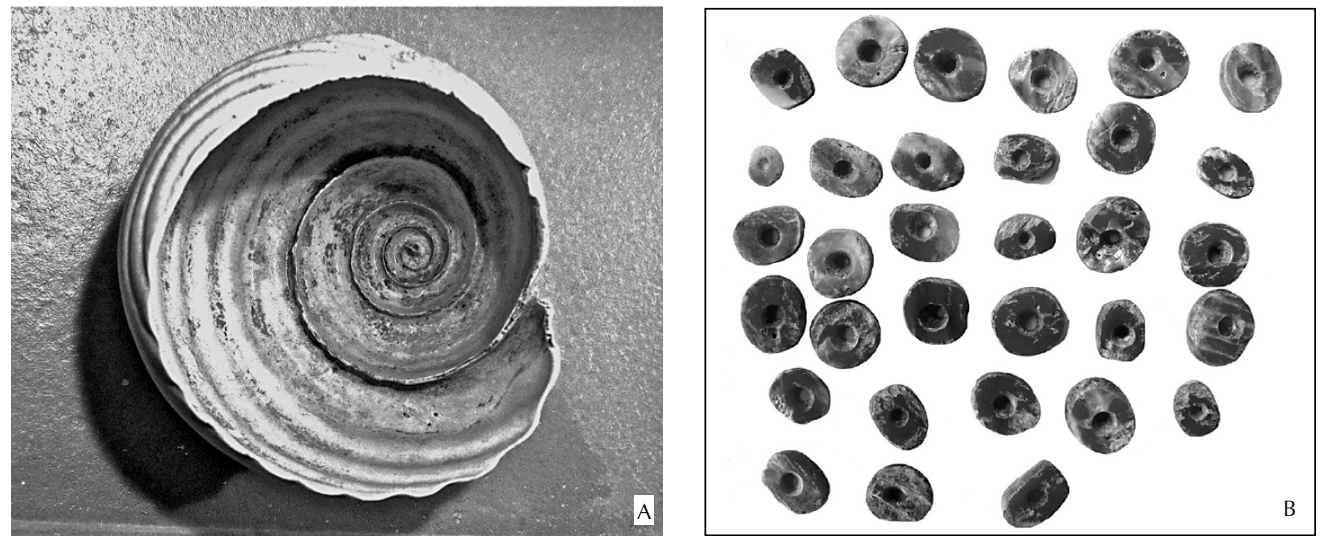

Figura 5 - A: Recipiente hecho de caracol (tola J4b) B: Cuentas de Spondylus (tola J7)

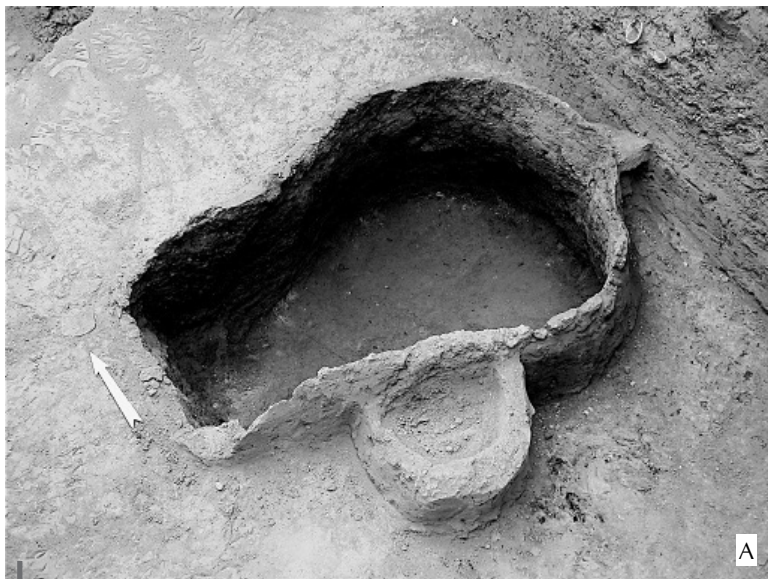

Figura 6 - A: Horno (tola J5)

B: Hornos manabitas culinarios (tola J6)

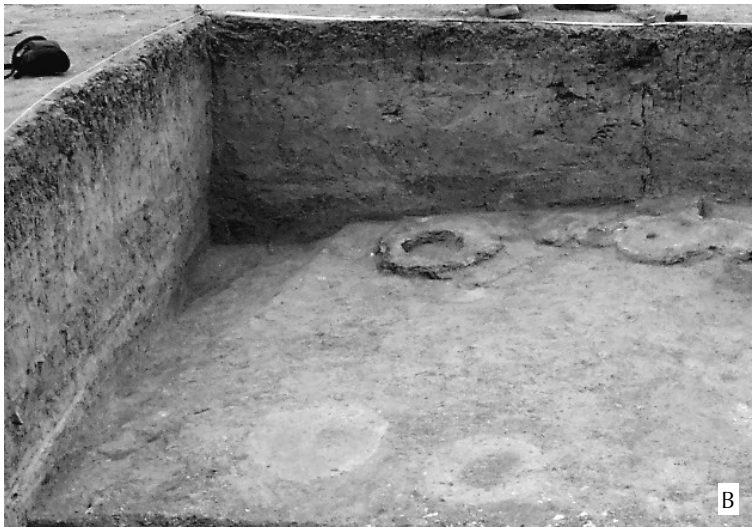


de palmas...). Este tipo de construcción no dejó muchas huellas cuando los materiales desaparecieron de forma natural como ocurrió probablemente. En este caso preciso, solamente quedó el piso como vestigio arqueológico tangible. Es probable que este piso haya sido intencionalmente quemado para obtener un suelo más cómodo y agradable (Bouchard et al., 2006). Otra hipótesis es la de un incendio de la casa ocasionando el mismo efecto sobre el piso, pero, en este caso preciso, faltan evidencias que normalmente quedan acumuladas después de un incendio (cenizas y carbón vegetal en gran cantidad, mezclados con vestigios culturales rotos y quemados...).

También se han descubierto talleres: en la tola J4 donde aparecen evidencias de varias etapas de fabricación de elementos de adorno en conchas de argopecten: más de dos mil elementos perforados muestran que varias «manos» expertas (masculinas y/o femeninas) ejercían su actividad artesana (Guinea, 2006).

Toda esta serie de rasgos descubiertos en las excavaciones permiten confirmar la hipótesis de un asentamiento humano residencial y de grandes dimensiones durante el último periodo precolombino.

La estratigrafía misma revela también que muchos montículos de Japoto han sido las bases de las viviendas de la gente nativa. Ya se ha subrayado el hecho de que esas tolas son plataformas elevadas para edificar construcciones en su cumbre (Bouchard et al., 2006). En las estratigrafías obtenidas, se nota que se han realizado, a lo largo del tiempo, trabajos de mantenimiento que se traducen por la acumulación de estratos apisonados superpuestos: corresponden a los rellenos y a los suelos de dichas habitaciones de la gente nativa manteña. Esto significa que la evolución diacrónica del sitio Japoto pasa después del primer asentamiento por un proceso de construcción de plataformas (las tolas), con mantenimientos adicionales que han producido la topografía artificial que se aprecia en nuestros días.

Sin embargo, como lo han mostrado los niveles más profundos, en varias ocasiones la ocupación humana indígena empieza en los tiempos más remotos a un nivel inferior, y muy probablemente sin mayor modificación del relieve natural.

En varias tolas (por ejemplo J3, J5, J6) existen pisos ocupados a una profundidad que es inferior de varios metros a la cumbre de las plataformas y que han sacado a la luz evidencias de ocupación en épocas remotas.

El mayor hallazgo de este tipo fue realizado al excavar la tola J8 en 2007 y 2008. En efecto, fue una gran sorpresa descubrir que 38 no se asemejaba a las demás tolas del sitio (ver Guinea en este volumen). Solamente se quiere destacar que aquí no se presenta una estratificación de pisos, como en las otras tolas, puesto que existe una ocupación anterior a la tola y que esta se adecua a la topografía natural (fig. 3). Sería atrevido proponer una identificación precisa para esta construcción antigua, sobre todo porque la arqueología de la época manteña no proporciona referencias parecidas. Sin embargo, puesto que no hay huellas domésticas en el nivel sacado a la luz, debemos buscar otra interpretación³. En una excavación, la ausencia de

3 La morfología de la estructura de adobe y de sus componentes se define como un elemento principal en forma de banqueta baja, con un murete que forma un respaldar. Esta banqueta está apoyada 
vestigios domésticos lleva el arqueólogo a suponer que no es un espacio doméstico y por lo tanto que puede ser «algo» público (civil, religioso o político...). Es un hecho sumamente significativo el descubrir en medio de tolas habitacionales un recinto público que podía reunir a gente de elite dentro de un espacio no habitacional.

En efecto, una construcción tan grande como la que apareció debajo de la tola J8 no debió lógicamente existir en un sitio común como lo sería una humilde aldea poblada solamente por campesinos o pescadores. Cabe satisfacerse con esta hipótesis general que reforzaría la idea expresada desde un principio. El hallazgo de la estructura sepultada y de las numerosas huellas de la construcción precaria que la protegía era otro argumento relevante para suponer un estatus elevado para Japoto. Es decir que fue más que un simple asentamiento y que tuvo con toda probabilidad un papel más importante, tal vez a manera de centro regional de control y poder.

Finalmente, es obvio que gana mucho valor una ausencia notable: ningún otro sitio de importancia equiparable a Japoto parece haber existido en la región. Esto parece suficiente para calificar a Japoto como el mayor sitio en la llanura baja del Puerto Viejo.

\section{MEDIO AMBIENTE Y RECURSOS EN LA ALIMENTACIÓN}

En el Periodo de Integración, la producción agrícola que sostiene los pueblos nativos es la base de subsistencia predominante, entre otros con el maíz y con

en su lado este a un talud inclinado que se hunde a 3 metros de profundidad y forma un muro de contención o contrafuerte. Frente a la banqueta, al oeste, se extiende un espacio plano horizontal, quemado en totalidad por la caída del techo y de las paredes en llamas. Todo esto constituye un elemento de arquitectura interior, que es preservado hasta nuestros días. La hipótesis que se puede deducir de los datos es que ha existido encima de dicha construcción un gran techo construido en materiales vegetales secos que consiste en un armazón de cañas gordas (guadua) y cubierto de palmas. Esta «ramada» puede ser del estilo sencillo que todavía se usa en la construcción rural de las regiones costeras o bien de un estilo más fino y rebuscado puesto que estos materiales se prestan a muchos aspectos decorativos. De todos modos, un buen techo es indispensable para proteger la estructura de las abundantes y frecuentes lluvias del «invierno». Por un lado, el primer elemento arqueológico que aparece, a partir de $80 \mathrm{~cm}$ de promedio debajo de la cumbre de la tola revela la presencia de una pared de «adobes» hechos de tierra cruda, recubiertos de barro arcilloso. Luego, al extenderse la excavación para descubrir un máximo de vestigios fue claramente visible que todo el conjunto arquitectónico sepultado presentaba evidentes huellas de un incendio que endureció y fragilizó a la vez los elementos minerales (tierra arcillosa de los pisos, barro de los enlucidos, adobes). Los daños del fuego fueron importantes y afectaron a casi todo el espacio construido. No se puede saber si el incendio fue intencional o accidental. Este fue muy devastador porque, de ser un accidente, no fue posible apagar el fuego hasta que se quemaran todos los vegetales secos, probablemente por la falta de agua. Algunas paredes laterales estaban revestidas de quincha (caña + barro y fibras) como lo mostraban restos quemados con las improntas de vegetales. Se notó que se limpiaron las ruinas puesto que la mayor parte de los escombros calcinados han desaparecido. Pero no se reconstruyó en el lugar la misma arquitectura y, al contrario, se abandonaron los vestigios de tierra. Por lo tanto para protegerlas (o esconderlas) se ha acumulado una enorme cantidad de cascajo y tierra de relleno que resultó formar el núcleo de la tola J8. Es notable ver que dicha decisión se asemeja a la costumbre frecuente (en otras culturas) del enterramiento ritual de los templos y de la arquitectura monumental. 
otros alimentos vegetales específicos de la región. Pero, una gran parte de las proteínas animales provienen del agua. Quiero insistir en los importantes recursos naturales del medioambiente acuático para la gente de Japoto.

En primer lugar fueron incluidos todos los peces cuyos vestigios (espinas, escamas, huesos) han sido descubiertos en grandes cantidades en la mayoría de las tolas excavadas. El estudio que realizó Philippe Béarez fue sumamente llamativo: si bien predominaban especies del mar litoral o del estuario, existían también algunas especies que no solían acercarse a las costas y que se obtenían usualmente mar adentro. Se confirmó, por lo tanto, la capacidad de navegar lejos de las playas y no solamente por medio de la pesca con redes desde el litoral. Para toda la cultura manteña la existencia de fibras vegetales como el algodón nos permite sustentar la hipótesis de fabricación de cuerdas para redes y sedales. También existen varios ejemplos de anzuelos de cobre, descubiertos en Japoto, que sustentan la hipótesis de la pesca. Por otra parte, es preciso notar que Béarez reconoció que los restos de fauna que él pudo estudiar indicarían más bien que el tamaño de los peces consumidos era importante: es decir que hubo probablemente una selección para favorecer presas de buen peso y no peces más pequeños, tal vez de menor valor. En este caso sugerimos que la mejor parte de la pesca llegaba al sitio Japoto, o sea alimentaba a las elites y gentes de alto rango, mientras que los pescadores se quedaban con los peces menos atractivos, como suele suceder hoy. Actualmente, es muy llamativo ver que la pesca diaria que se practica en las playas de San Jacinto y San Clemente, desde la misma orilla de la playa, produce una cantidad de menudos peces que ni siquiera entran en el consumo humano y se venden para hacer harina de pescado.

A continuación vienen algunos datos que pudieron ser establecidos por Béarez sobre la fauna ictiológica de Japoto (cuadro 1):

«Se han identificado alrededor de 50 taxones distintos. De ellos, 4 taxones son tiburones, o sea peces cartilaginosos. En el resto predominan los carangidaes (casi un $30 \%$ de los determinados):

- Caranx caninus - burro

- Selene spp. - caras

- Caranx otrynter - cojinova

Luego son numerosos también los sphyraenidés, o barracudas:

- Sphyraena spp. - picudas

Y las siguientes familias (hasta $8 \%$ de los determinados):

- los haemulidaes - roncadores

- los scombridaes - atún, bonito negra, rayada, albacora

- los ariidaes - bagres» (Béarez,2006).

En segundo lugar, los restos de moluscos comestibles abundan en los niveles arqueológicos. Entre otros, destaca la anadara tuberculosa (o concha negra) tan popular en nuestros días y que se obtiene en los suelos lodosos de los manglares. También hay ostras, ostiones, algunos otros bivalvos (almejas), conos y caracoles. 
Japoto: sitio manteño residencial de la costa central de Manabí

Cuadro 1 - Frecuencia de grupos o familias de peces, en número de restos determinados (NR) número mínimo de individuos (NMI) y peso de restos en gramos $(\mathrm{P})$

\begin{tabular}{|l|c|c|c|}
\hline GRUPO O FAMILIA & NR & NMI & P (g) \\
\hline Carangidae & $29,8 \%$ & $28,2 \%$ & $44,6 \%$ \\
\hline Sphyraenidae & $12,9 \%$ & $12,2 \%$ & $5,5 \%$ \\
\hline Haemulidae & $10,3 \%$ & $10,2 \%$ & $3,5 \%$ \\
\hline Scombridae & $10,1 \%$ & $7,7 \%$ & $4,2 \%$ \\
\hline Ariidae & $8,0 \%$ & $7,5 \%$ & $8,9 \%$ \\
\hline Sélaciens & $7,4 \%$ & $7,5 \%$ & $6,8 \%$ \\
\hline Tetraodontidae & $5,5 \%$ & $8,0 \%$ & $7,2 \%$ \\
\hline Sciaenidae & $3,7 \%$ & $5,5 \%$ & $7,7 \%$ \\
\hline Malacanthidae & $3,3 \%$ & $3,6 \%$ & $2,2 \%$ \\
\hline Lutjanidae & $3,1 \%$ & $4,7 \%$ & $5,9 \%$ \\
\hline Polynemidae & $2,2 \%$ & $1,1 \%$ & $0,6 \%$ \\
\hline Clupeidae & $0,7 \%$ & $0,6 \%$ & $0,2 \%$ \\
\hline Synodontidae & $0,7 \%$ & $0,3 \%$ & $0,1 \%$ \\
\hline Triglidae & $0,6 \%$ & $1,1 \%$ & $0,5 \%$ \\
\hline Hemiramphidae & $0,6 \%$ & $0,3 \%$ & $0,1 \%$ \\
\hline Serranidae & $0,4 \%$ & $0,8 \%$ & $0,8 \%$ \\
\hline Centropomidae & $0,1 \%$ & $0,3 \%$ & $0,9 \%$ \\
\hline Sparidae & $0,1 \%$ & $0,3 \%$ & $0,3 \%$ \\
\hline Coryphaenidae & $0,1 \%$ & $0,3 \%$ & $0,2 \%$ \\
\hline Total determinados & 672 & 362 & 926,5 \\
\hline Indeterminados & 429 & - & 107 \\
\hline Total general & 1101 & 362 & 1033,5 \\
\hline & & & \\
\hline & & $\%$ & $\%$ \\
\hline
\end{tabular}

La existencia actual de vestigios de manglar en la punta norte del estuario nos indica que no había dificultad para recolectar dichos moluscos comestibles cuando los manglares tenían una mayor extensión, no muy lejos de Japoto en tiempos precolombinos. También, suponemos el consumo de crustáceos por su abundancia natural (langostinos, camarones, cangrejos...). Finalmente, un molusco especial como alimento son los caracoles terrestres comestibles, recolectados en épocas húmedas del invierno. Estos se han encontrado en varios basureros de Japoto, son de buen tamaño y a veces tan numerosos que no hay duda sobre su consumo. Por otra parte, no podemos descartar el papel de una cacería de animales terrestres (venados, roedores, aves, reptiles...).

En conclusión, es obvio que para los grupos del litoral pacífico, la pesca y la recolección de alimentos marinos han sido una riqueza importante que permitió 
su buen desarrollo. La agricultura costera tenía grandes riquezas alimenticias como el maíz, los fréjoles y otras leguminosas, la yuca, el maní, muchas frutas. Además la presencia de venados y varios animales terrestres podía complementar una dieta ya generosa y variada.

Se puede suponer que la escasez de agua para el riego y para el consumo fue un obstáculo mayor, aunque la construcción de canales de riego y de «albarradas» (o jagüeyes) mejoró las condiciones naturales (Marcos et al., 2004).

\section{VESTIGIOS CULTURALES: DE LO UTILITARIO A LO SUNTUARIO}

Entre los vestigios materiales descubiertos en las excavaciones, sobresalen los artefactos de cerámica, y sobre todo los recipientes. Se refiere nuevamente al estudio dedicado a la cerámica realizado por K. Stothert. Ella señala con mucho énfasis que no es homogénea la cerámica de los recipientes puesto que existe una importante cantidad de «vajilla de etiqueta», según sus propias palabras (Stothert, 2006). Así, la cerámica de Japoto nos revela también un alto estatus que se puede interpretar como la evidencia de una población de elite conforme a nuestra hipótesis de trabajo mencionado al principio del estudio.

Obviamente, en toda residencia de elite, deben coexistir ambas clases de vasijas: «la vajilla culinaria» y la «vajilla doméstica común» que no aparecen en los eventos ceremoniales o rituales y «las vasijas suntuarias o de etiqueta». En Japoto, es impresionante la cantidad de adornos y de motivos decorativos presentes en las vasijas, cuando, por lo general, la cerámica manteña no es precisamente de las más adornadas y decoradas.

Después del estudio de K. Stothert, dos temporadas de excavación han aportado más materiales y quiero agregar nuevos datos a su estudio, aunque este sigue vigente en general. Confirmamos la relativa abundancia de elementos que pertenecen más bien a la vajilla decorada, o sea «de etiqueta», y vale la pena evocar aquí ejemplos llamativos de decoración para ilustrar este aspecto.

\section{1. Decoraciones figurativas en relieve}

Se trata de un tipo de decoración que viene a «personalizar» las vasijas y que las hace únicas puesto que cada motivo está hecho individualmente (fig. 7). Sin embargo hay algunas categorías que se pueden reconocer.

Una categoría especial es la decoración con «mascarones» utilizada frecuentemente como adorno sobre la pared externa de una vasija: una cara humana estilizada en la cual se detallan con relieves cóncavos y convexos los ojos, la nariz, la boca y a veces las orejas, con elementos suntuarios como aretes, bezotes o narigueras.

Otra categoría es la figuración modelada de la cabeza de un personaje humano (a veces, con torso), hecha en relieve tridimensional, que forma una parte específica de una vasija. En el caso de las «compoteras», es frecuente que la parte media, más 
Japoto: sitio manteño residencial de la costa central de Manabí
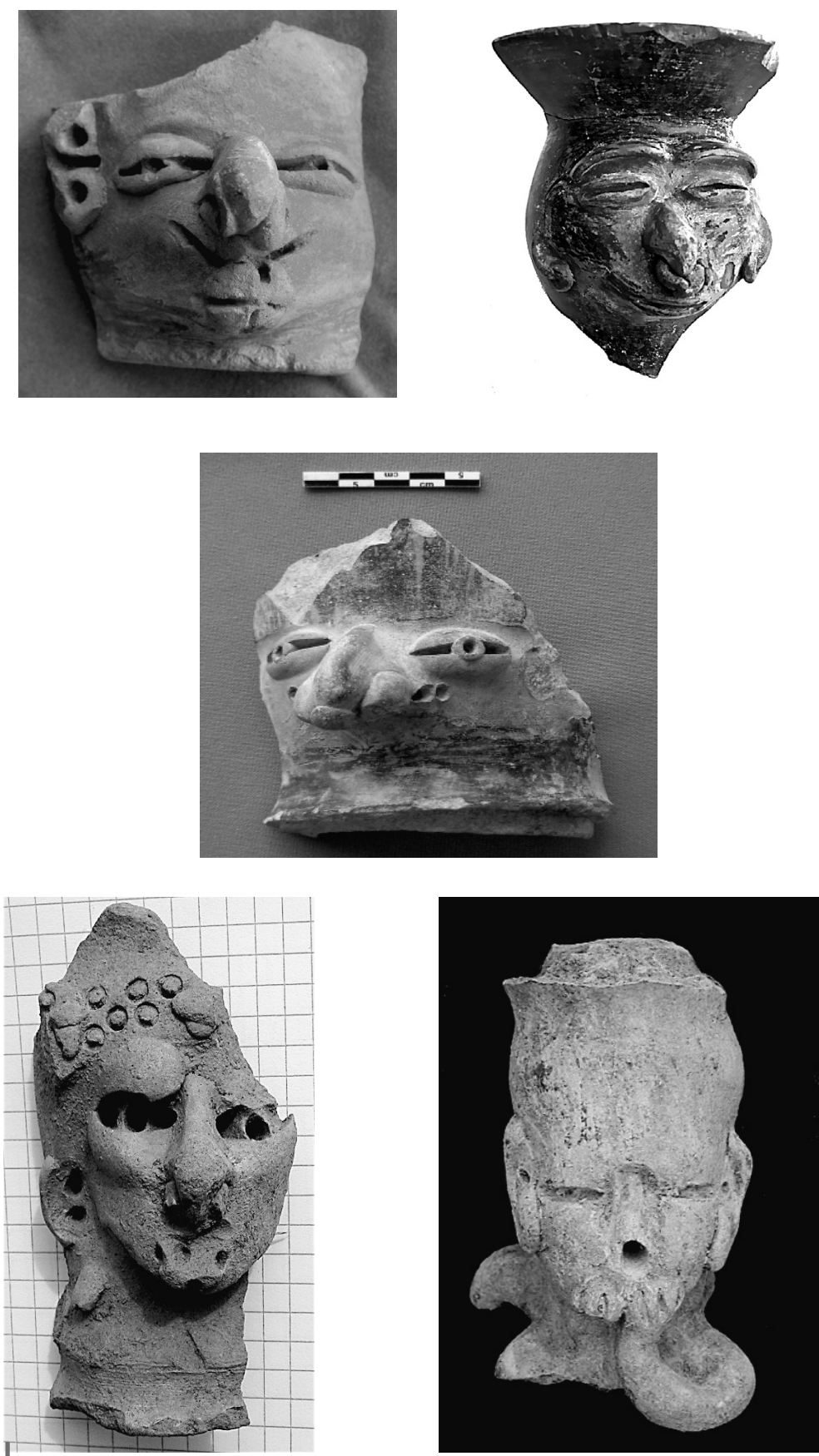

Figura 7 - Decoraciones antropomorfas en relieve sobre la cerámica de Japoto 
estrecha, tenga este tipo de decoración. Las facciones humanas se representan de forma exagerada o bien estilizada.

Finalmente, existen algunas evidencias de vasijas modeladas de forma figurativa. Sus paredes muestran en relieve una cara humana un poco a manera de las vasijas «retrato». También es frecuente el uso de un adorno modelado estilizado de forma animal. En Japoto, el más abundante representa un ave marina, el pelícano, con su largo pico que reposa sobre la garganta. En este caso la frecuencia de la representación de este animal puede corresponder a un papel especial del ave, tal vez como animal preferido, simbólico o totémico, puesto que en otros sitios parece que no hay representaciones de pelícanos sino de otros animales como zarigüeyas.

\section{2. Decoraciones gráficas figurativas: motivos pintados y grabados de estilo graffiti}

En este renglón debemos también poner aparte las decoraciones «figurativas» que son poco comunes y pueden ser indicios de un estatus de importancia para las vasijas. Sin embargo, en el caso de los grabados graffitis puede existir una duda sobre su presencia sobre la vasija «en vida» o sobre la realización del motivo inciso sobre un tiesto después de la «muerte» de ella. O tal vez han existido las dos modalidades: ejecutar el graffiti sobre la vasija y ejecutarlo sobre un tiesto después de la rotura de la vasija (fig. $8 \mathrm{~A}$ y $\mathrm{B}$ ).

Al parecer, los motivos figurativos pintados se han hecho con destreza, cuidadosamente y de forma programada. No son muy numerosos ni hay motivos enteros completos, sin embargo reconocemos muy claramente tres casos «excepcionales»: una representación humana (de la cual queda solamente una parte del personaje de pie) y dos representaciones de aves vistas de perfil con un pico fuerte y voluminoso. En los tres casos se nota el contraste entre un gris muy negruzco con un gris más claro que forma una especie de «blanco y negro» (en positivo o en negativo). En todos los casos, el artista-artesano realiza un motivo sobre una parte de la vasija relativamente plana, su tamaño es relativamente pequeño y afecta solamente una parte de la vasija, aunque puede ser asociado a otros motivos no figurativos.

En cambio, los motivos grabados graffitis tienen un tipo de ejecución menos cuidadosa (tal vez se debe también a la dificultad de grabar sobre una superficie resistente). La palabra graffiti expresa muy bien el aspecto espontáneo, menos cuidadoso, aunque se puede a veces reconocer una libertad y un estilo naif muy llamativos. La verdad es que parece difícil interpretar bien esta forma tan especial de decorar las paredes de cerámicas.

Entre los demás vestigios materiales que se han descubierto, algunos pueden ser interpretados como los indicios de la presencia de gente de varios niveles sociales. Todos estos se pueden agrupar bajo el epígrafe de elementos para modificar la apariencia humana tan importante al parecer para significar el estatus de los 
Japoto: sitio manteño residencial de la costa central de Manabí
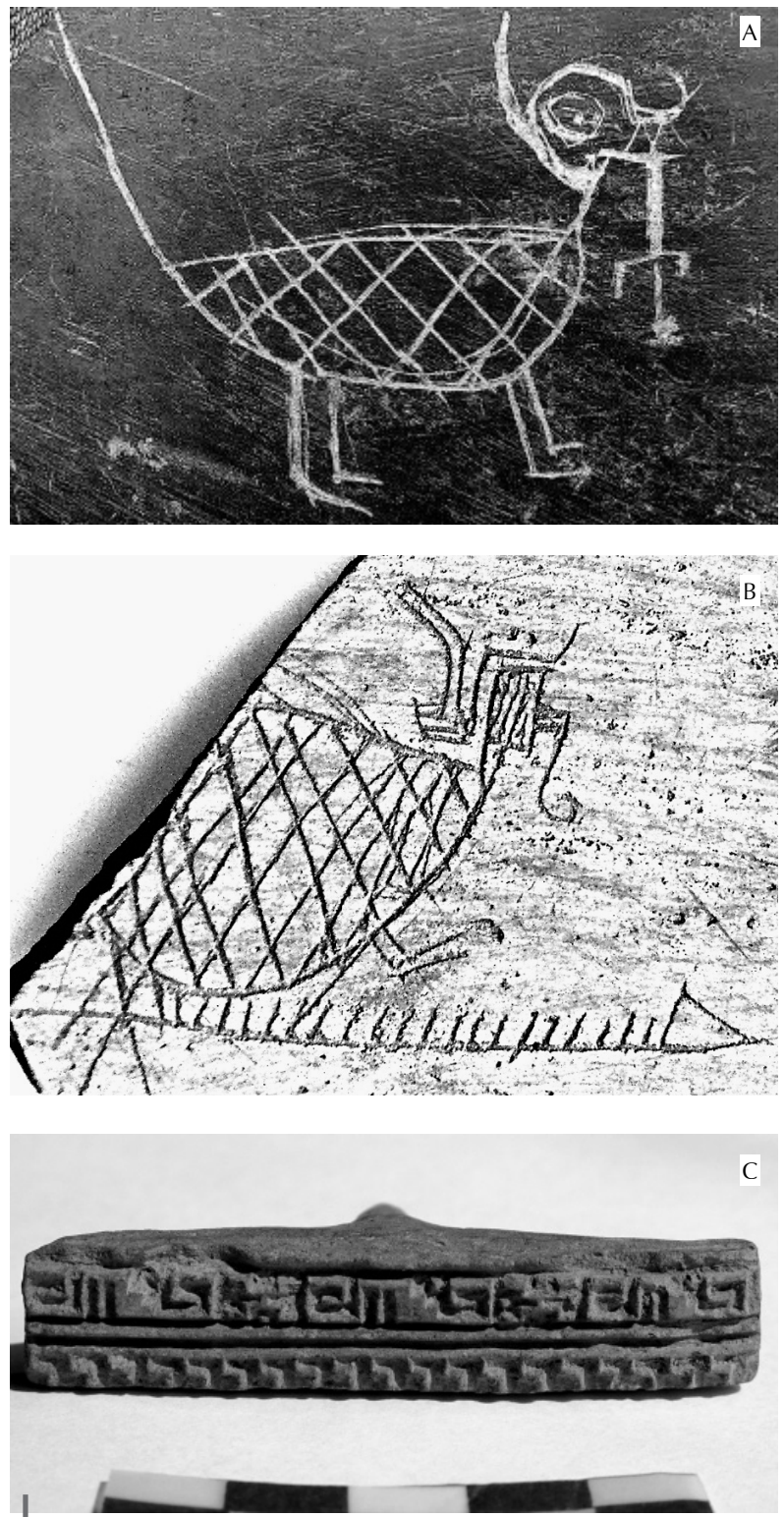

Figura 8 - A: Cuadrúpedo inciso sobre cerámica

B: Dragón inciso sobre cerámica

C: Sello estampador

personajes. Podemos tomar el ejemplo de los adornos corporales que muy a menudo se tallaron en concha de moluscos marinos o dientes de tiburón. No se trata de objetos de gran tamaño ni de objetos complejos elaborados con muchos elementos. También existen varios ejemplos de «sellos» para estampar motivos 
sobre la piel 4 o sobre ropa y telas (fig. $8 \mathrm{C}$ ). Otros elementos insignes de estatus son posibles adornos faciales de metal (cobre) (inarigueras?). Es también notable el hallazgo de una pinza de cobre: esta suele ser considerada en la literatura como una pinza para depilarse el vello corporal, lo que también modifica la apariencia.

\section{PRÁCTICAS CULTURALES: DE LA VIDA A LA MUERTE}

En varias de las tolas estudiadas se han descubierto sectores funerarios. Unos parecen ser una reorganización posterior de huesos humanos o sea enterramientos secundarios y otros parecen corresponden más bien a enterramientos primarios que se han hecho de forma provisional (tola J7) o definitiva (tola J6) (fig. 9). Por lo general los enterramientos descubiertos carecen de ofrendas dispuestas con el cuerpo de los difuntos, salvo algunos casos de posibles ofrendas sencillas y sin valor5. En el caso de la tumba en la tola J6, el esqueleto viene acompañado de unos fragmentos de cerámica (tiestos) sobre los huesos y no es por lo tanto una ofrenda mayor. La literatura especializada no documenta hallazgos de sepulturas manteñas especialmente ricas, como las que se han descubierto en los países vecinos de Colombia y Perú, e inclusive en el mismo Ecuador, sobre todo para culturas anteriores al Periodo de Desarrollo Regional. Es de destacar que a veces se supone que las sepulturas de la elite no se localizan en sitios de vivienda sino en lugares aislados (Stothert, comunicación personal). Japoto podría ser un ejemplo más que ilustra la ausencia de tumbas ricas junto a las habitaciones. Sin embargo, en la tola J7, aparentemente un montículo natural utilizado con fines mortuorios, con 20 individuos de varias edades, se han descubierto tres elementos relevantes.

Por un lado se trata de dos figurines de cerámica relacionados con una sepultura de niño: ambos figurines son macizos y modelados. Uno representa un batracio, otro una mujer desnuda con un abdomen voluminoso, significando que la mujer está encinta. Para Delabarde (2006), su asociación con una sepultura podría tener un significado de promesa o de deseo de una nueva fertilidad, tomando en cuenta además que a menudo los batracios son reconocidos símbolos de la fertilidad en el mundo prehispánico. De ser así, tendríamos un caso claro de la asociación de

4 Algunos cronistas dicen que la gente tenía tatuajes corporales o «cara labrada». Es preciso preguntarse si esto no fue una interpretación errónea de motivos impresos sobre la piel con los sellos de cerámica.

5 Es notable que pocos enterramientos corresponden a la totalidad de los esqueletos de los individuos: es decir que faltan algunos huesos y, a veces, hasta la misma cabeza. Es posible que la «pérdida» de una parte de las osamentas tuviera lugar al pasar los esqueletos de un lugar a otro, lo que puede suceder al vaciar una sepultura para depositar los huesos en una urna (reducción de sepultura) o para conformar un «paquete» funerario... También es posible que el difunto no fuera enterrado desde el principio con la totalidad de sus huesos como en el caso en una sepultura de la tola J7 donde se descubrió un cuerpo extendido de cúbito dorsal pero sin la cabeza. Esta no apareció en este lugar, aunque se encontraron dientes humanos con los huesos. El estudio de los vestigios humanos estuvo a cargo de la antropóloga Tania Delabarde, quien excavó además las sepulturas de la tola J7 (Delabarde, 2006). 
Japoto: sitio manteño residencial de la costa central de Manabí
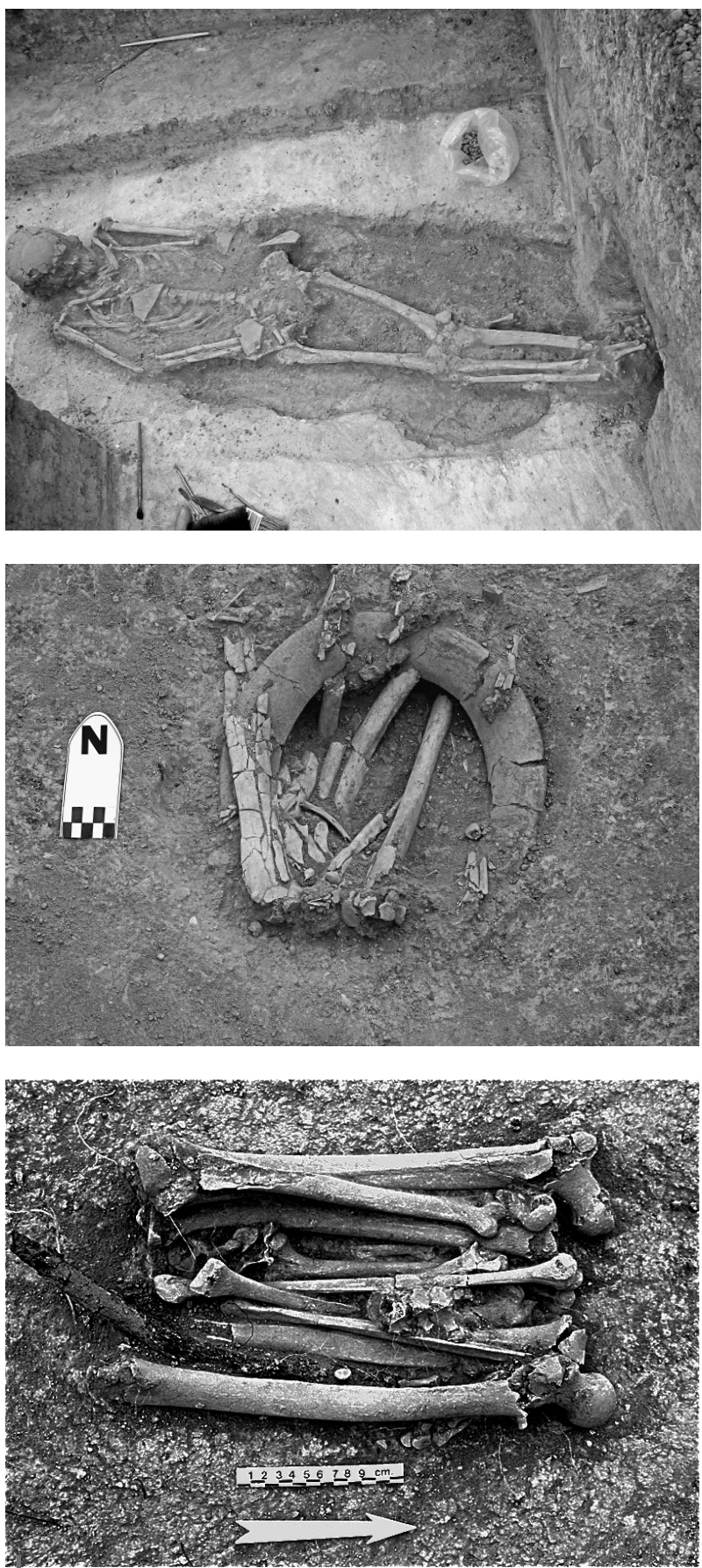

Figura 9 - A: Sepultura primaria (Tola J6); B: Urna funeraria y huesos (Tola J6); C: Huesos largos (Tola J7) 
restos humanos (o sea de la muerte) con una evocación de la vida por nacer, tal vez en reemplazo de la criatura difunta.

En otro caso, en el fondo de un recipiente cerámico incompleto se ha descubierto un conjunto de 32 cuentas de spondylus, todas con una perforación cónica (fig. 5B). Esto podría constituir el segundo ejemplo de ofrenda singular en el sitio. Sin embargo, no queda muy clara la asociación: la ofrenda fue descubierta en una fosa de planta circular, en las cercanías del sector mortuorio del montículo J7, pero no junto a una sepultura precisa.

Por lo tanto, en Japoto (por lo menos, en estas excavaciones) es notable la ausencia de enterramientos con un importante ajuar funerario de valor. Puede ser el indicio de que los más poderosos difuntos se han sepultado aparte en tumbas especiales y fuera del mismo sitio habitacional, como dijimos anteriormente.

\section{POSIBLES INTERPRETACIONES}

En Japoto, las investigaciones concurren en dar la imagen de un pueblo donde se han dado actividades diversas, algunas de las cuales no serían precisamente propias de una sencilla aldea poblada de trabajadores populares. Para esta zona, no tenemos registro de nombres de otros pueblos cercanos ni de verdaderos hallazgos científicos de aldeas precolombinas. Según toda lógica, es obvio que la llanura baja del río Puerto Viejo necesitaba ser controlada. Además, sus oportunidades logísticas no podían ser desaprovechadas: cercanía del medio acuático para la pesca y para el comercio marítimo, presencia de buenas tierras aluviales para la agricultura. Raramente estas condiciones favorables se presentan juntas en estas regiones y los manteños supieron sacar ventaja de ellas creando el pueblo de Japoto. Más al norte, la presencia de acantilados hasta Bahía de Caráquez se suma a la ausencia de ríos hasta el Chone impidiendo crear un asentamiento importante. Más al sur, el relieve de la costa tampoco se presta a recibir un pueblo importante. Además, es muy probable que la esfera de control territorial por parte de la Jocay manteña (hoy, Manta) se ejerciera varios kilómetros hacia el norte de dicha ciudad.

Es notable que en la actualidad, el pueblo de Charapoto, ubicado a escasos kilómetros del sitio arqueológico hacia el interior del valle, retoma parte del papel jugado anteriormente por el asentamiento prehispánico, mientras los balnearios de San Jacinto y de San Clemente cumplen con la actividad pesquera pequeña. Por varias razones la ciudad de Puerto Viejo, que es ahora la capital provincial del Manabí, se alejó del mar pero se mantuvo a la orilla del mayor río de la región para seguir conectada con el mar.

Toca ahora evocar las palabras más de moda que son las de señoríos y caciques. Se repite desde hace mucho tiempo que la mayoría de los grupos precolombinos complejos de los Andes fueron organizados en «jefaturas» o sea cacicazgos, también llamados «señoríos». En la región manteña se suele considerar que hubo por lo menos 3 grandes cacicazgos, entre los cuales el de Salangone tuvo prelación 
en varios estudios hasta hacerse famoso tal vez por su importancia efectiva y tal vez por haber tenido la «suerte» del encuentro de un barco español con una de las balsas de este señorío. De allí nació la fama del cartel del mullu, de la liga marítima y otros nombres que buscaron resaltar su importancia en el pasado. De tal modo que casi es un paso obligado cuestionarse por lo menos sobre los señores manteños.

Parece difícil tomar el ejemplo de los cacicazgos de la América andina tardía para buscar sus orígenes en épocas cronológicas muy remotas. Pero tratándose ahora de los últimos diez siglos antes de la Conquista, parece más aceptable la referencia a los supuestos señoríos.

No hay duda de que estas poblaciones costeras tuvieron un nexo predilecto con el mar. En su mayoría, los pueblos de la costa encontraban proteínas en el océano y en la playa. Pero no en todas la regiones se enfatizaba su carácter de pueblos navegantes: entre estos sobresalen, en el Perú, los comerciantes pescadores de Chincha y los tumbesinos, en el Ecuador, los puneños (o punaes) y los manteños huancavilcas. Es muy interesante ver que estos últimos dominaron la zona de vida natural del spondylus que fue objeto de un comercio tan especial en los Andes. Todos conocen ya las páginas escritas sobre el tráfico de mullu y los demás intercambios realizados por los manteños. No hay inconveniente alguno en interpretar el periodo Atacames tardío como una posible evidencia de sus incursiones en la costa norte del Ecuador (y aun del sur de Colombia). Sobre todo si se considera que el tráfico del mullu tuvo que responder a una mayor demanda en los tiempos tardíos como parece ser demostrado6 (Noriega, 2007). Si el Señor de Chincha (dentro del imperio Inca) era muy poderoso y se desplazaba cargado en andas en presencia del Inca Atahualpa, es porque su flota de varios miles de balsas autorizaba este privilegio único. Por lo tanto cabe relativizar el poder de los Señores manteños, sin aminorarlo tampoco.

A la par de los pueblos de la Sierra y de la Selva, los pueblos de la Costa también supieron dominar y superar los obstáculos naturales de su propio medio ambiente. A diferencia de los pueblos serranos que supieron calcular las épocas favorables para las siembras, adaptar sus cultivos a las vertientes y los cultígenos a la altura, los pueblos costeños han desarrollado también una agricultura específica de tierras áridas. Pero también se dedicaron a adaptarse al peligro del mar, de sus tormentas y de la fuerza de las olas. Estos aspectos, entre otros logros, les aportaron su riqueza y su dominio, no sobre las tierras sino sobre el mundo acuático y marítimo, llegando a formar un desarrollo cultural y económico digno de nuestra admiración. La riqueza de los pueblos marítimos vino de la posibilidad de sacar gran cantidad de alimentos del océano y también de comerciar a media

6 «[...] alrededor del 600 DC hay cambios drásticos en la forma en que el Spondylus era importado a los Andes Centrales [...] El más relevante de estos cambios [...] es el cambio que Shimada nota en la parafernalia ritual, en particular con respecto al alto incremento de conchas Spondylus» (Noriega, 2007). A continuación, el autor señala que hubo otro aumento significativo en la importación de conchas Spondylus en el Periodo Intermedio Tardío, especialmente de la cultura Chimu. 
y larga distancia sin la necesidad de entrar en territorios hostiles. En efecto, para poder efectuar un transporte terrestre se necesita el control absoluto de las rutas y territorios, es decir, se tiene que tener el paso libre y se debe transitar en terrenos seguros o aliados. En cambio, el comercio marítimo necesita solamente tener un puerto de salida y un puerto de destino seguros sin tener temor a pueblos belicosos. La cosa parece sencilla pero requiere la capacidad de navegar a veces durante un largo plazo y poseer la pericia especializada que tuvieron los pueblos costeros navegantes del Pacífico andino.

Es posible que en la jerarquía de los señoríos manteños, Japoto no tuviera un rango equiparable a Agua Blanca, posible capital del famoso señorío de Salangone. Nadie dijo que los señoríos y señores manteños tuvieran el mismo rango y más bien podemos pensar que existían unos fuertes y mayores, mientras otros se mantenían a un menor nivel como fue el caso en otras regiones andinas. Hasta ahora es difícil proponer interpretaciones más complejas, pero tal vez el estudio de Japoto lleve a conocer mejor la organización social, económica y política de los manteños.

Por otra parte, se nota que las formas de aprovechar el medio ambiente han variado mucho desde la época de la Conquista. Al contrario de lo que ocurre con el asentamiento Jocay/Manta, Japoto es un caso que muestra el desplazamiento de un lugar a otros lugares para la vivienda humana y para las manifestaciones concretas del poder. Sin embargo, esto tiene una inmensa ventaja para la cultura del presente. En efecto, mientras en Manta no subsiste nada visible de la Jocay prehispánica, Japoto conserva sus vestigios del pasado precolombino casi intactos. Se debe insistir sobre un hecho evidente: en Japoto, los montículos son la traducción en el espacio de la ocupación humana precolombina que ha modificado de forma definitiva el paisaje natural. No es tan común en el Ecuador tenerlo claramente a la vista y de fácil acceso. Vuelvo a subrayarlo aquí puesto que Japoto es una excelente muestra de la forma cómo las poblaciones nativas han intervenido sobre el paisaje. Es cierto que las tolas no son «ruinas» espectaculares como los edificios incas o mayas pero todavía están a la vista y es un deber conservarlas así. En efecto, destruirlas para establecer salineras, camaroneras o cultivos modernos, no es solamente cambiar el paisaje sino borrar de la memoria la vida de los antepasados nativos, o sea cometer uno de los peores atentados a la cultura humana. Mejor dicho, es aceptar que la parte nativa e indígena de las raíces culturales del país desaparezca en beneficio de intereses económicos que las desprecian por completo. El juicio del futuro en cuanto a esto puede ser distinto de la indiferencia actual y pasada sobre esta destrucción. Se ha intentado aportar las pruebas de que estos vestigios tienen valor y merecen ser estudiados y conservados para guardar presentes los logros de los amerindios del Ecuador.

Para terminar, conviene comunicar una noticia alentadora que puede aportar esperanzas sobre esta conservación. El 18 de septiembre de 2008, el municipio del Cantón Sucre declaró que Japoto (o sea la finca donde excavó el equipo) se reconocía como un espacio cultural, arqueológico y ambiental. Por lo tanto se prohibían en el lugar actividades que ponían en peligro los vestigios culturales: 
cultivos, remoción de tierra, arado, etc. Para todo el grupo de investigación y para todos los que valoran el pasado precolombino fue un acontecimiento de gran importancia que abría el paso a una perspectiva muy positiva para el porvenir del sitio.

\section{Referencias citadas}

BOUCHARD, J.-F., FUENTES, F. \& LÓPEZ, T., 2006 - Aldeas y pueblos prehispánicos en la costa de Manabí: Chirije y Japoto. Bulletin de l'Institut Français d'Études Andines, 35 (3): 243-256.

BÉAREZ, P., 2006 - Rapport de mission en Équateur : étude des vestiges osseux de la faune marine du site de Japoto. Informe interno, sin publicar.

DELABARDE, T., 2006 - Una secuencia de patrones funerarios manteños en la provincia de Manabí. Primeros resultados de la tola J 7 (Japoto). Bulletin de I'Institut Français d'Études Andines, 35 (3): 313-320.

ESTRADA, E., 1957 - Prehistoria de Manabí, 176 pp.; Guayaquil: Archivo Histórico del Guayas.

GUINEA, M., 2006 - Un sistema de producción artesanal de cuentas de conchas en un contexto doméstico manteño: Japoto. Bulletin de l'Institut Français d'Études Andines, 35 (3): 299- 312.

MARCOS, J., ALVAREZ, S., VEINTIMILLA, C., TOVAR, O. \& VALVERDE, F., 2004 - Las albarradas del Ecuador, 372 pp.; Guayaquil: ESPOL.

MORALES Y ELOY, J., 1942 - Atlas del Ecuador; Quito: Ministerio de Relaciones Exteriores.

NORIEGA, A., 2007 - El intercambio de Spondylus a lo largo de la costa sudamericana de acuerdo al registro arqueológico. In: II Congreso ecuatoriano de antropología y arqueología (S. García Serrano, ed.): 433-460; Quito: Abya-Yala.

SAVILLE, M., 1907 - The antiquities of Ecuador, vol. 1; New York: Heye Museum.

STOTHERT, K., 2006 - La cerámica de etiqueta de las tolas de Japoto (costa de Ecuador). Bulletin de I'Institut Français d'Études Andines, 35 (3): 265-298.

TOUCHARD, A., 2006 - Una casa manteña puede esconder otra. Evaluación preliminar de la tola $\mathbf{6} 6$ de Japoto (Manabi). Bulletin de I'Institut Français d'Études Andines, 35 (3): 285-298. 